\title{
Quality improvement of rockbolting
}

\author{
Y. Yokota Technical Research Institute, Kajima Corporation, Japan
}

T. Yamamoto Technical Research Institute, Kajima Corporation, Japan

K. Date Technical Research Institute, Kajima Corporation, Japan

T. Mori Technical Research Institute, Kajima Corporation, Japan

\begin{abstract}
Recently, owing to advances in tunnel support and reinforcement techniques, NATM (New Austrian Tunnelling Method) has been increasingly used even for large section tunnels, squeezing tunnels and shallow tunnels in urban areas. Therefore, the authors have focused on improving the quality of rockbolting and have developed a technique for diagnosing the installation condition of rockbolts using ultrasonic waves, high-friction anchored rockbolts using checkered steel pipes and a simplified axial force measurement device using a light emitting converter (LEC). This paper presents the details of each development and actual applications of these new techniques to several sites. All results confirmed the effectiveness of these three techniques.
\end{abstract}

\section{$1 \quad$ Technique for diagnosing the installation condition of rockbolts using ultrasonic waves}

Rockbolts that are fixed in place with mortar are generally used in mountain tunnels. However, in areas where there is a large amount of water inflow, it is difficult to fill pore spaces due to the spillage of joint material. Therefore, there is concern that this might harm the long-term stability of the support functions. Consequently, the authors developed equipment that uses ultrasonic waves to detect and clearly display small reflective signals in order to get a good understanding of the state of filling and help to improve the quality of the rockbolting. This chapter will report on the results of laboratory and in situ tests that were conducted using the filling ratio as a parameter.

\subsection{Study principles and the developed equipment}

In addition to the ultrasonic wave technique for measuring the length of rockbolts, the present study also included a method for getting a clear understand of filling conditions by focusing on small reflective signals that are generated on the boundary between the bolt and the joint material.

Figure 1 shows a diagram of the measurement principles. When there is good fill, the ultrasonic waves pass straight through the bolt and are reflected at the end of the bolt, rather than at the boundary with the joint material. On the other hand, if there is not a good filling condition, then the data will contain many measurements of small signals that were reflected from empty pore spaces.

Figure 2 shows a view of the developed equipment. The transmitted waves were burst waves. This increased the proportion of basic oscillating frequencies. Furthermore, there was a large output of generated ultrasonic waves. In addition, the LOG amplifier could display details of weak signals that were received. This enabled the detection of weak reflective signals that were generated at the boundary between the bolt and the joint material. The directivity of the ultrasonic waves depended on the inputted frequency and so the authors confirmed that the small reflective signals that were generated on the boundaries had a different signal (Mori et al., 2007). Therefore, the specifications of the equipment were chosen to confirm that this equipment was able to generate different frequencies of ultrasonic waves and analyse the reflective signals that were obtained from multiple frequency bands. 

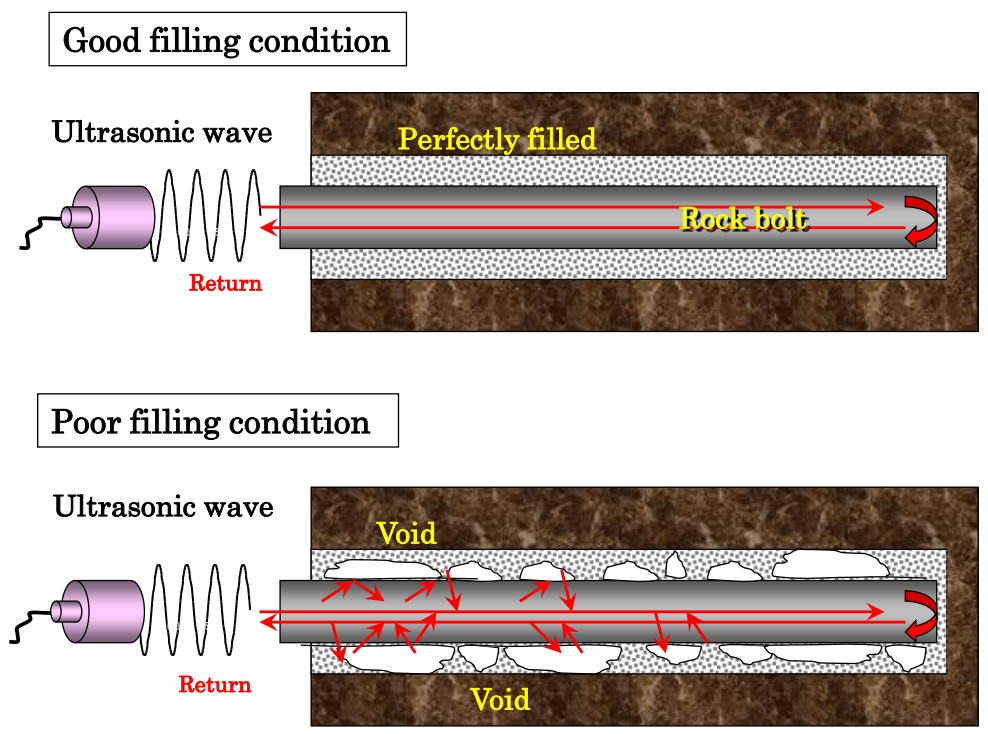

Figure 1 Diagram of the measurement

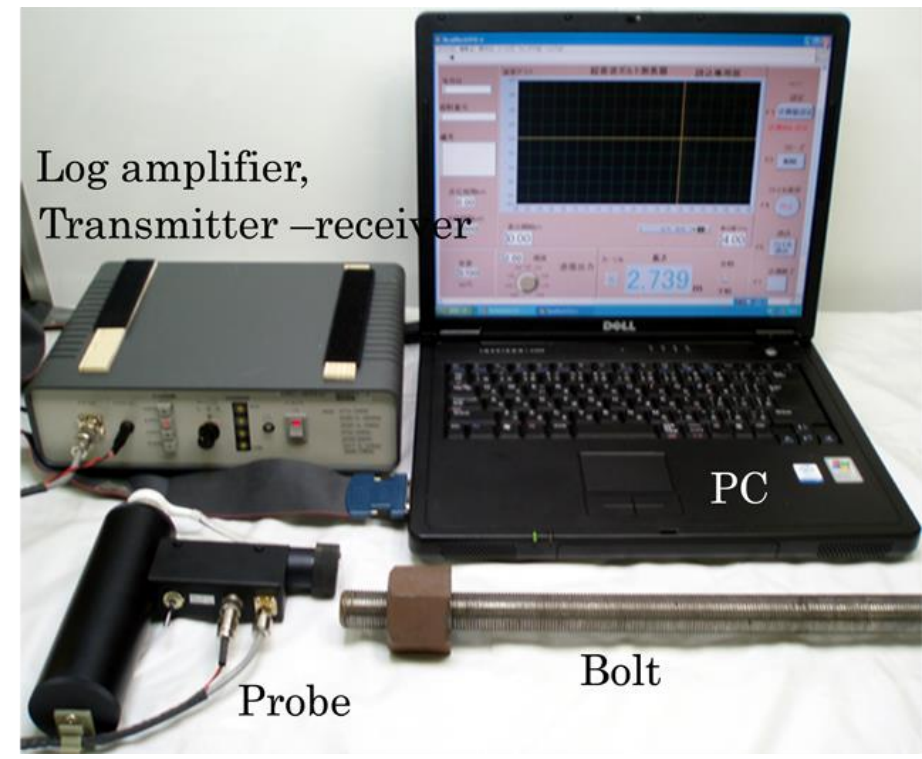

Figure 2 View of the developed principles equipment
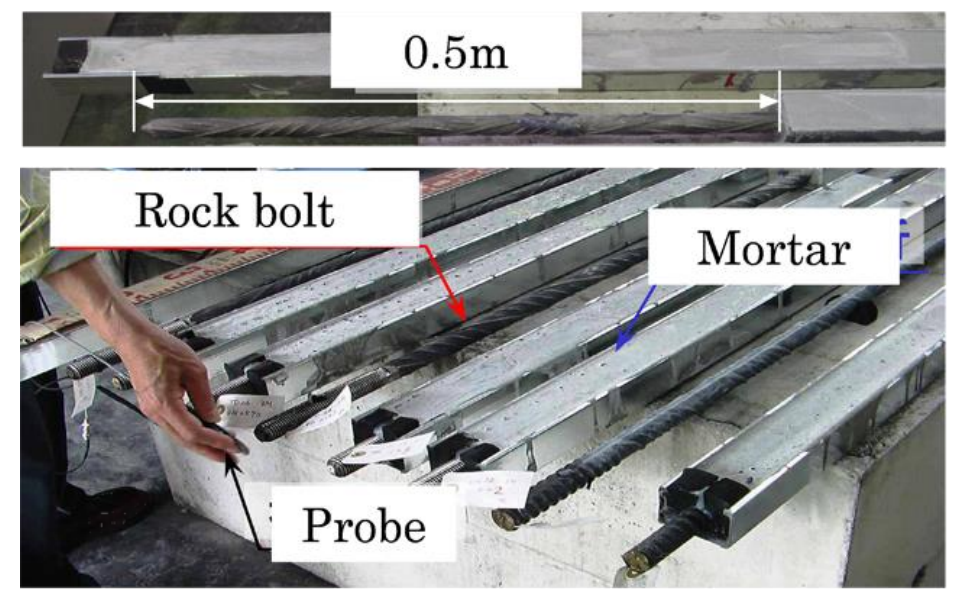

Figure 3 View of the laboratory tests 
Table 1 List of test cases

\begin{tabular}{cccccc}
\hline Case & Filling Ratio (\%) & Unfilled Locations & Case & Filling Ratio (\%) & Unfilled Locations \\
\hline 1.1 & 100 & Completely filled & 2.1 & 100 & Completely filled \\
1.2 & 83.3 & Edge side $0.5 \mathrm{~m}$ & 2.2 & 83.3 & Near side $0.5 \mathrm{~m}$ \\
1.3 & 66.7 & Edge side $1.0 \mathrm{~m}$ & 2.3 & 66.7 & Near side $1.0 \mathrm{~m}$ \\
1.4 & 50 & Edge side $1.5 \mathrm{~m}$ & 2.4 & 50 & Near side $1.5 \mathrm{~m}$ \\
1.5 & 33.3 & Edge side $2.0 \mathrm{~m}$ & 2.5 & 33.3 & Near side $2.0 \mathrm{~m}$ \\
1.6 & 16.7 & Edge side $2.5 \mathrm{~m}$ & 2.6 & 16.7 & Near side $2.5 \mathrm{~m}$ \\
1.7 & 0 & No mortar & 2.7 & 0 & No mortar \\
\hline
\end{tabular}

\subsection{Result of the laboratory tests}

Figure 3 shows a view of the laboratory tests. Table 1 is a list of test cases. Case 1.1 is completely filled (filling ratio $F=100 \%$ ). Case 1.1 was created as follows: $3 \mathrm{~m}$ rockbolts were installed in channel steel, and mortar was injected completely around the bolt. In Case 1.2, F was 83.3\%; after measuring Case 1, $0.5 \mathrm{~m}$ of mortar was shaved from the end of the rockbolt. In Case 1.3, F was $66.7 \%$, with a further $0.5 \mathrm{~m}$ of mortar shaved off (total $1.0 \mathrm{~m}$ ). In Cases 1.4 through 1.7, the specimens were all created in the same way, and then each case was subjected to ultrasonic wave measurements. In Case 1.7, there was no mortar fill ( $F=0 \%)$. In addition, with the specimens for Cases 2.1 through 2.7, the mortar was shaved off from the near side. In all cases, three types of frequencies were used: $2.18 \mathrm{MHz}, 3.00 \mathrm{MHz}$, and $3.88 \mathrm{MHz}$.

Figure 4 shows typical wave patterns that were received. The horizontal axis represents the distance from the oscillating equipment (calculated by multiplying the propagation velocity by the reflection time and dividing the product by 2 ). The vertical axis represents the oscillation amplitude level that was outputted through the LOG amplifier. Figures $4(a)(b)(c)$ indicate that as the filling ratio decreased (empty pore spaces increased), the waves reflected from the boundaries became dominant and the small reflective signals could be clearly confirmed from among the observation data. Next, there was a focus on differences in oscillation frequencies. When the filling ratio was high, there was little variance in all of the wave patterns, regardless of the frequency. On the other hand, when the filling ratio was low, there was much variance in all wave patterns obtained from all of the oscillation frequencies. This may have been because the directivity of the ultrasonic waves differed for each oscillation frequency, so that differences may have been generated in reflective signals received from boundary areas. In addition, Figure 4(d) shows the results of the cases with a high filling ratio of $83.3 \%$. Despite this high filling ratio, we can see that the generated small reflective signals were large. The sound pressure of the generated ultrasonic waves decreases as distance from the oscillating equipment increases. The reason why the generated small reflective signals were large may have been that the sound pressure of the ultrasonic waves was relatively large near the head side of the bolts, and the small reflective waves generated in the vicinity were also relatively large. From these results, it was concluded that this equipment can be used to estimate the mortar filling ratio and unfilled locations using analyses of small reflective signals. 


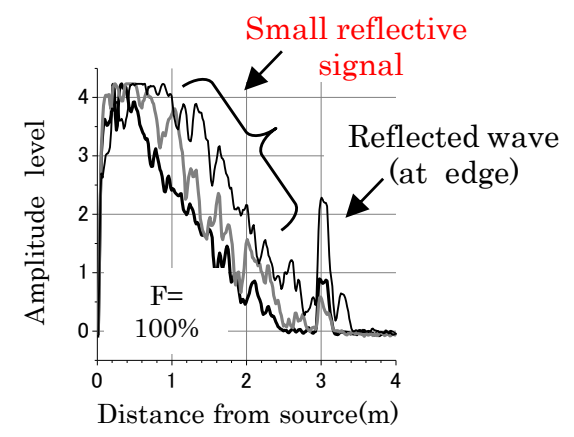

(a)

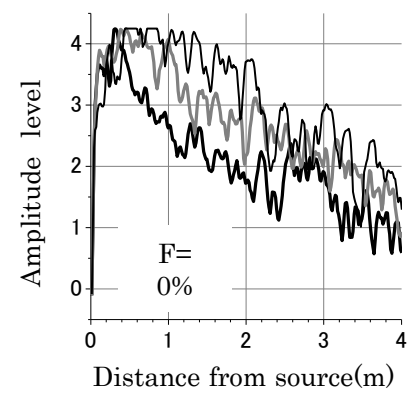

(c)

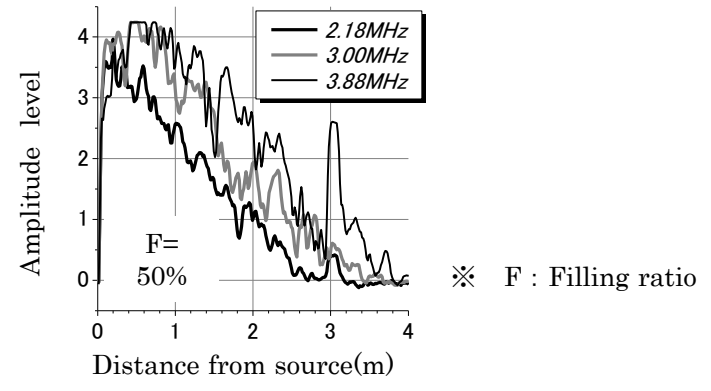

(b)

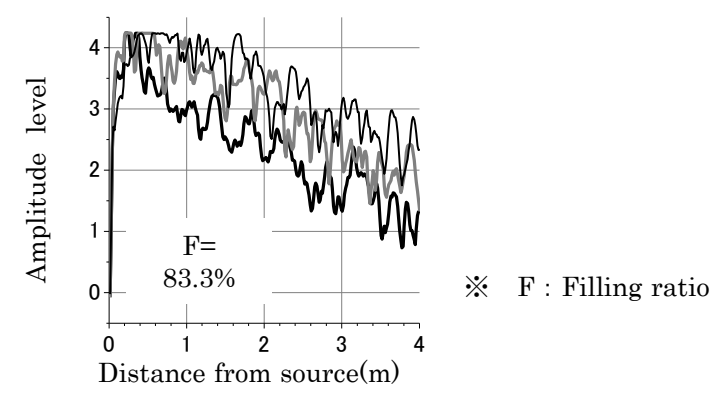

(d)

Figure 4 Typical waves patterns; (a) Case 1.1; (b) Case 1.4; (c) Case 1.7; (d) Case 2.2

\subsection{Results of the in situ tests}

Following are some examples of the application of this equipment in the actual site. It was used in standard geological zones and zones of water inflow. Figure 5 shows a view of the measurements. Figure 5 shows an example of received wave patterns that were determined to represent differences in filling ratios. Figure 6(a) shows a wave pattern that was received at a standard zone. The small reflective signal is very small, and each wave pattern is uniform, regardless of the oscillatory frequency. For comparison, Figure $6(\mathrm{~b})$ shows the wave pattern received from a water-inflow zone. The small reflective signal is large, and there is a noticeable effect of the oscillatory frequency. Based on information obtained in the laboratory, Figure 6(a) was evaluated as having good filling conditions, while Figure $6(\mathrm{~b})$ was estimated to have poor filling conditions.
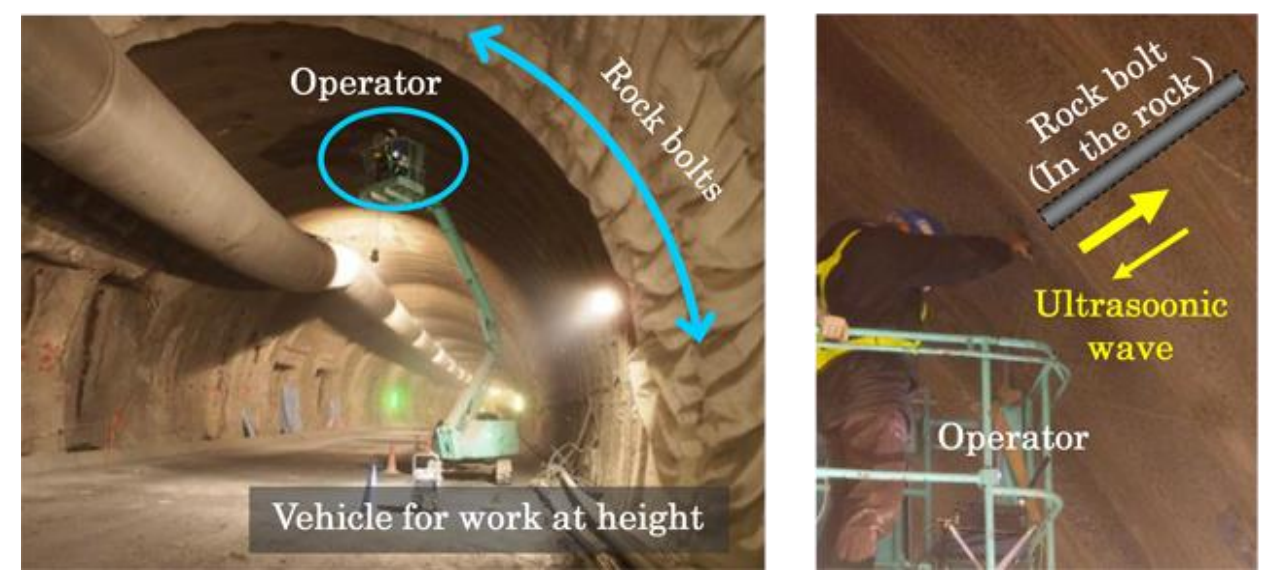

Figure 5 View of the measurements 


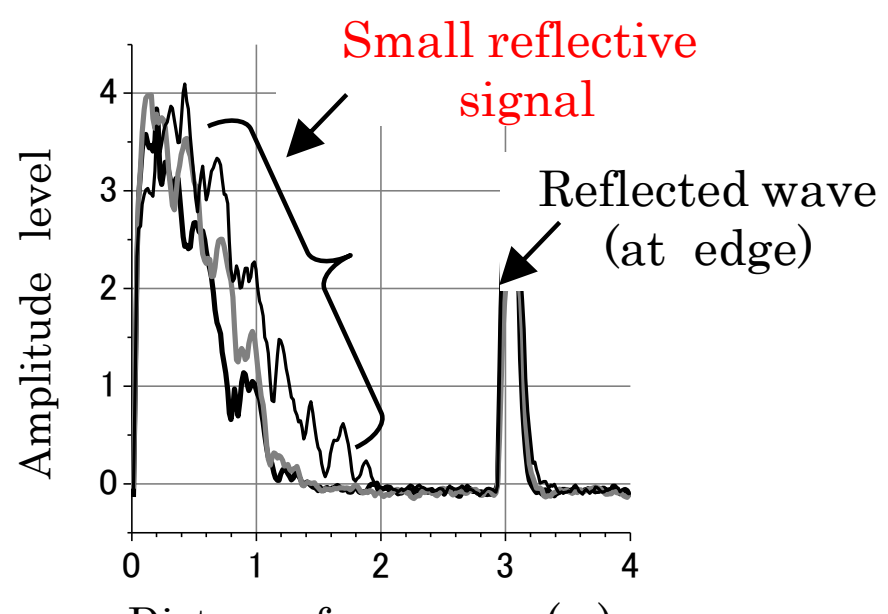

Distance from source $(m)$

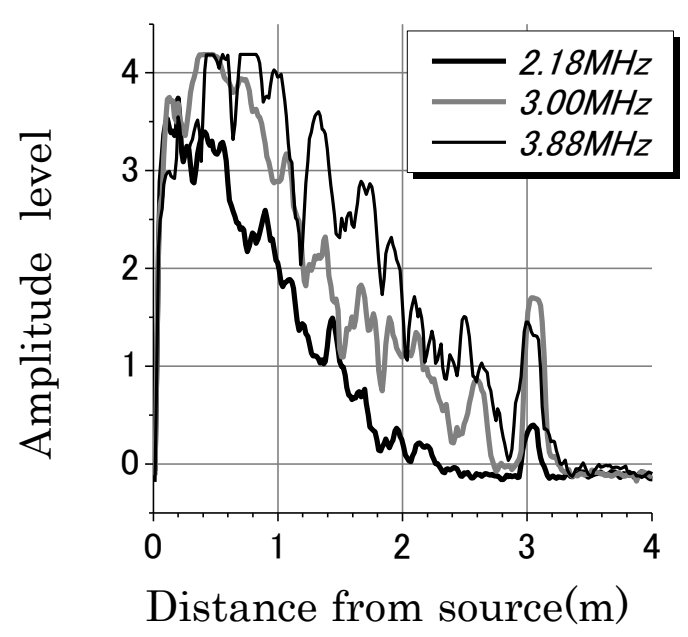

(b)

Figure 6 Example of received wave patterns; (a) standard zone; (b) water-inflow zone

In this way, estimates could be made of the state of the joint material in this system, even at an actual site, indicating the possibility for using this method to evaluate the soundness of rockbolts.

\section{$2 \quad$ High-friction anchored rockbolts using checkered steel pipes}

High-friction anchored rockbolts using checkered steel pipes are used in areas where there is a large amount of water inflow, and when it is desirable to obtain reinforcement effects of supports quickly after excavation. However, it is difficult to obtain sufficient bonding strength between the rockbolts and the ground due to factors such as rough borehole walls. Thus, when the bonding strength decreases, the supporting effects also decrease. As a result, there is concern that this can cause problems with the cost and construction period of the project, because it may become necessary to increase the number of rockbolts and the length to which they are installed.

In order to ameliorate this situation, the authors developed high-friction anchored rockbolts using checkered steel pipes. This new method adds protruding striations to the surface of steel pipes to improve the bonding effect of the pipes. This section will describe the new rockbolts, and examine the results of pull-out tests conducted in the laboratory and at an actual site, the verification results of the reinforcement mechanism using granular Distinct Element Method (DEM), and examples of application in the field.

\subsection{Description of the high-friction anchored rockbolts using checkered steel pipes}

Normal friction anchored rockbolts, which can show a bonding effect instantaneously, are inserted after excavation and are then expanded using water pressure. Consequently, they are now often used in ground conditions where filling and hardening of the joint materials is difficult due to water inflow, and also in ground that requires immediate supporting effects of the rockbolts. However, in soft ground containing mudstone, the borehole walls can become unstable, and the pull-out strength cannot be guaranteed to be equal to that of rockbolts fixed in place with mortar, because the bonding effect between the steel pipes and the ground decreases in such ground. To solve such problems, the authors developed a high-friction expansion-type of steel pipe. The surfaces of the new steel pipes come with protruding striations, as can be seen in Figure 7 (Yokota et al., 2011). Figure 8 shows an overview of the new rockbolts, while Table 2 lists the specifications of the bolts. 


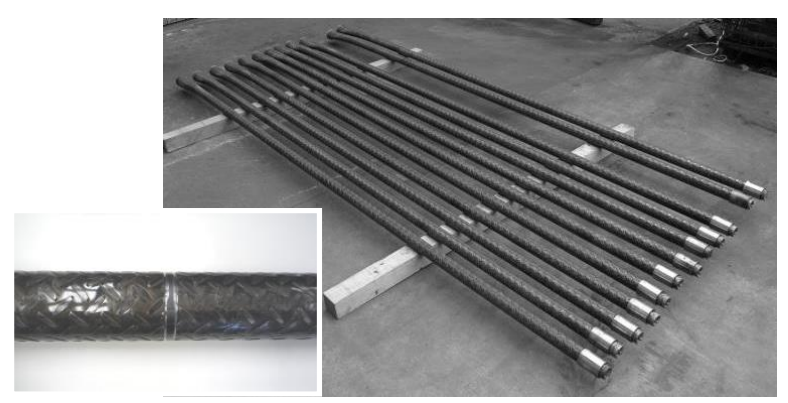

Figure 7 The surfaces of the new steel pipes

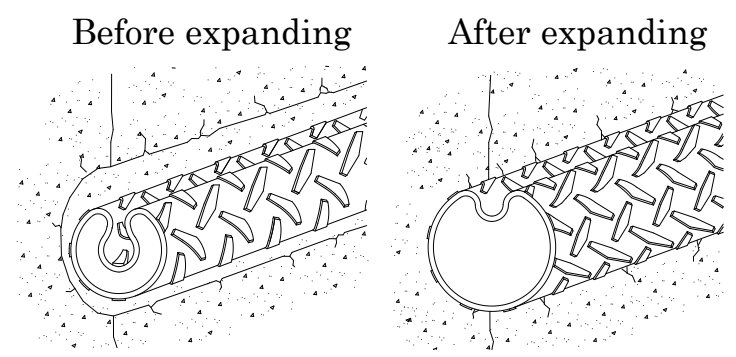

Figure 8 Overview of the new rockbolts

\subsection{Result of pull-out test}

Pull-out tests were conducted in the laboratory and in the field in order to verify the bonding effects of the high-friction anchored rockbolts using checkered steel pipes. For comparison, tests were also conducted using normal friction anchored rockbolts.

\subsubsection{Laboratory tests}

The testing method was as follows: First, the rockbolts were inserted in $1 \mathrm{~m}$ steel tubes that acted as model boreholes. Next, water pressure was used to expand the rockbolts, which were then pressure-attached to the model boreholes. Finally, pull-out test equipment was installed on the heads of the bolts, and pull-out tests were conducted using a hydraulic jack. In these tests, the pull-out load and displacement of the bolt heads were measured. Figure 9 shows the results of the tests. The new high-friction anchored rockbolts using checkered steel pipes were confirmed to have two times the bonding strength of normal friction anchored bolts in test conditions. In addition, when the high-friction anchored rockbolts using checkered steel pipes were used, the pull-out load showed a tendency to slightly increase after the pull-out strength peak was reached. In contrast, with the normal friction anchored bolts, the pull-out load tended to decrease remarkably after the pull-out strength peak. This may have had something to do with the shape of the surface of the steel pipes, which presumably has a great impact on the reinforcement effect after the pull-out strength reaches its peak.

\subsubsection{In situ tests}

The procedure for the pull-out tests conducted on actual sites was as follows: First, rockbolts were inserted into boreholes that were drilled $3 \mathrm{~m}$ into the wall sections of tunnel sides. Then, the rockbolts were expanded with water pressure to attach them to the borehole walls. Finally, pull-out test equipment was installed, and pull-out tests were conducted using the hydraulic jack. Figure 10 shows the conditions for the in situ pull-out tests. The geology of the tunnel was inconsistently soft, finely fractured mudstone. At the test site, the crown had settled about 30 to $40 \mathrm{~mm}$, and about 50 to $60 \mathrm{~mm}$ of convergence had occurred. Figure 6 shows the results of the in situ tests. As with the lab test results, the new high-friction anchored rockbolts using checkered steel pipes were confirmed to have two times the bonding strength of normal friction anchored bolts. In addition, in the in situ tests, differences were seen in the behaviour of the bolts after the pull-out strength peak. The bonding strength of the new high-friction anchored rockbolts using checkered steel pipes did not decrease after the peak. Furthermore, these rockbolts showed a very large 
graph slope during the initial pull-out. Consequently, we could conclude that the new bolts had a greater effect in suppressing ground displacement than the conventional normal friction anchored bolts, even before the pull-out strength peak.

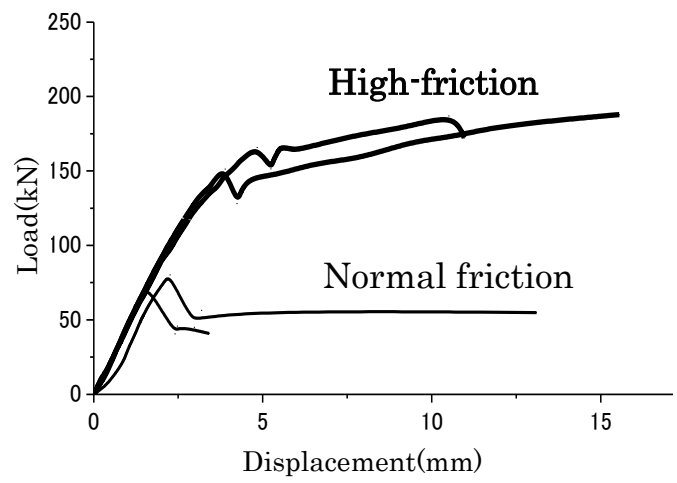

Figure 9 Results of the laboratory tests

Table 2 Specifications of the bolts

\begin{tabular}{ccc}
\hline & $\begin{array}{c}\text { High Friction } \\
\text { Anchored Rockbolt }\end{array}$ & $\begin{array}{c}\text { Normal Friction } \\
\text { Anchored Rockbolt }\end{array}$ \\
\hline External diameter $(\mathrm{mm})$ & $54(63.5)^{*}$ & $36(54)^{*}$ \\
Thick $(\mathrm{mm})$ & 2.3 & 2.3 \\
Yield load $(\mathrm{kN})$ & 180 & 191 \\
\hline
\end{tabular}

* After expanding

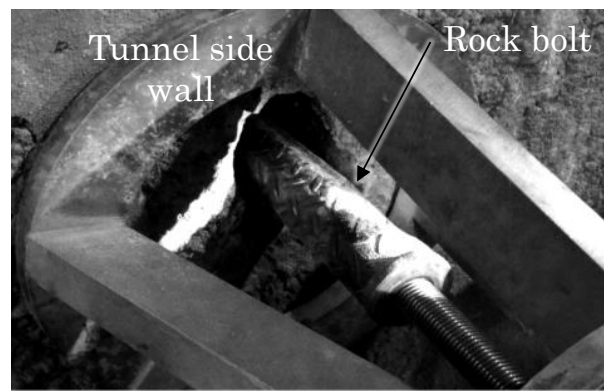

Figure 10 Conditions for the in situ pull-out tests

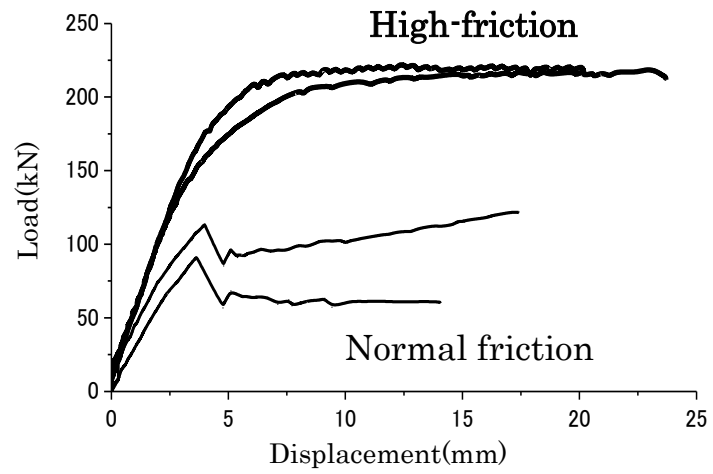

Figure 11 Results of the in situ tests 


\subsection{Numerical analysis to verify the reinforcement mechanism}

In the numerical analysis, the Granular Distinct Element Method (DEM) was used to examine the reinforcement mechanism of the new high-friction anchored rockbolts using checkered steel pipes. The pull-out tests were simply simulated to evaluate the phenomena that occurred in the rock during the pullout tests. In the granular DEM, individual specimens with random shapes were modelled by bonding numerous particles together. Then, simulations were made of the elastic behaviour of the individual specimens and the process by which the occurrence of cracking resulted in damage.

Figure 12 shows two analytical models. In the present study, parameters such as the diameter and length of the rockbolts, the height of the protrusions, the spacing of the arrangements, etc., were not accurately modelled because our primary goal was to verify differences in the reinforcement resulting from the presence or absence of protrusions. Furthermore, none of the expansion processes were simulated and the pull-out test simulation was started under conditions in which there was contact with the ground.

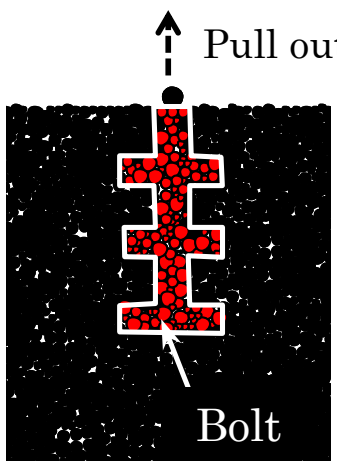

(a)

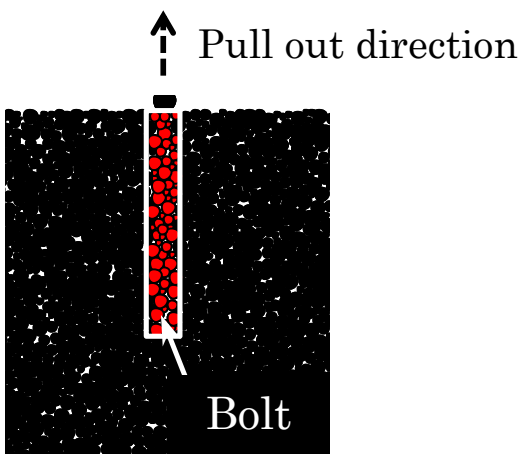

(b)

Figure 12 Two analytical models; (a) protrusion model; (b) flat model

Figure 13 shows comparisons of conditions under which there was cracking of the rock. In the protrusion model, there were few instances of the occurrence of tensile cracking and shear cracking compared with the smooth model. Furthermore, the cracking spread out in all directions. The shear cracking in particular progressed at a low angle from the vicinity of the protrusion, and its area of distribution was wide. On the other hand, in the smooth model, the distribution of tensile cracking showed close to a reverse triangular pattern, and the occurrence of cracking was concentrated in the vicinity of the bolts. Shear cracking occurred randomly in the vicinity of bolts.

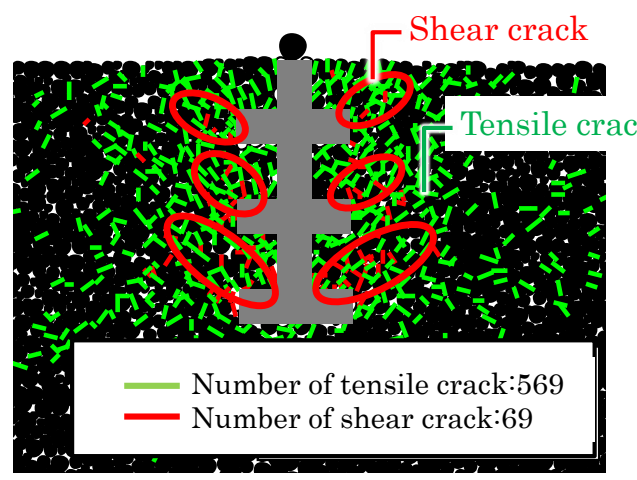

(a)

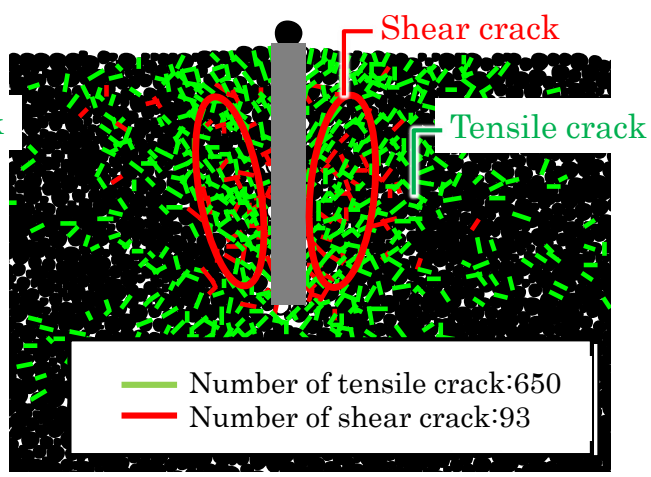

(b)

Figure 13 Comparisons of conditions under which there was cracking of the rock; (a) protrusion model; (b) flat model 


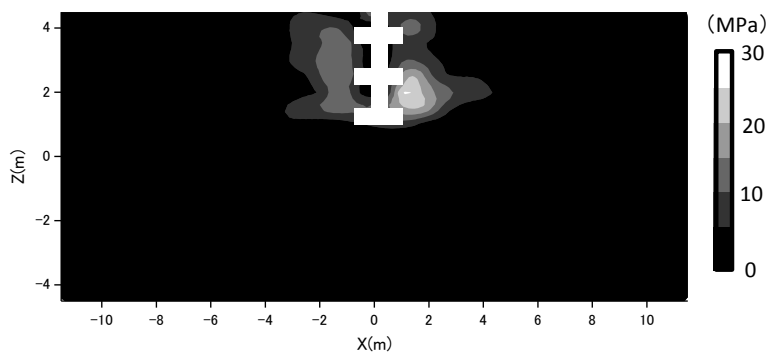

(a)

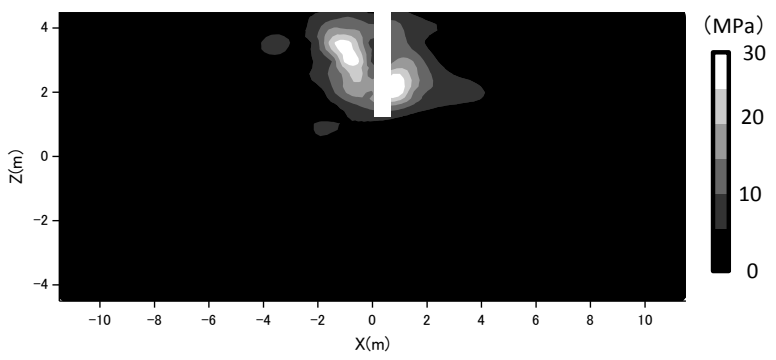

(b)

Figure 14 Comparisons of the distribution of stress in the surrounding rock; (a) protrusion model; (b) flat model

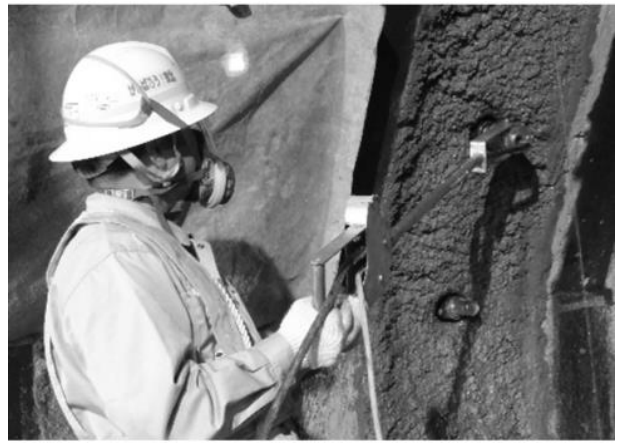

Figure 15 Installation conditions

Figure 14 shows comparisons of the distribution of stress in the surrounding rock. In the case of the smooth bolts, the stress was concentrated in the vicinity of the bolts. In contrast, the bolts with protrusions propagated stress in a wider area, and as we can see from the trends in the occurrence of cracking that the concentration of stress was lessened. These results are considered to be a local model of the high-friction anchored rockbolts using checkered steel pipes. Tensile and shear cracking occurred from the vicinity of the protruding sections during pull-out, and spread out in a wide area in the ground, dispersing the concentration of stress away from the bolts. As a result, we may also conclude that the pull-out strength was ultimately improved.

\subsection{Examples of applications in the field}

Six-metre-long high-friction anchored rockbolts using checkered steel pipes were installed near the tunnel shoulder in order to examine the workability of the new bolts. Figure 15 shows installation conditions. As a result, no problems such as loss of water pressure during water injection were seen. Furthermore, there were absolutely no problems with the insertability of the bolts.

\section{$3 \quad$ Simplified axial force measurement device using a Light Emitting Converter}

The previous sections reported on the techniques for evaluating the filling of rockbolts using ultrasonic waves, and high-friction anchored rockbolts using checkered steel pipes with improved bonding ability. The authors believe that the supporting effects of the rockbolts in the field should be quickly and easily evaluated, and feedback on their performance should later be used in order to improve the quality of rockbolt installation. For that purpose, the authors developed a new measuring method called simplified axial force measurement using an LEC. 


\subsection{Problems with conventional methods and outline of the development}

One of the most common methods for evaluating the behaviour of rockbolts has been axial force measurement using a strain gauge. However, the following are believed to be issues that may prevent the achievement of the above objectives:

- Only measuring companies can install the equipment.

- This increases the cost of taking measurements. In addition, conventional method can only be installed in limited areas (and the equipment cannot be easily used for other measurement points).

- Generally, the measurement results cannot be evaluated, except at the office at the site (and they cannot be evaluated in real time).

Therefore, the authors developed a simplified axial force measurement device using an LEC which meets the following specifications:

- The load cell uses a small measuring devices for anchors that can be easily installed and set. Consequently, any person on site can set up the equipment.

- The equipment can be removed using specially developed nuts. Even when there is a load, the equipment can be used for other rockbolts.

- The emitted light changes colour in stages in response to the load acting on the rockbolt plate. As a result, the axial force can be depicted visually in real time at the site.

- The measured data can be stored on an SD card. This can be used not only to visually depict the acquired data, but also to conduct detailed analyses.

Figure 16 shows the external appearance of the system. Table 3 lists the specifications of the pressure disk for the anchor. Values for responding to generating light colour can be freely set by the user.

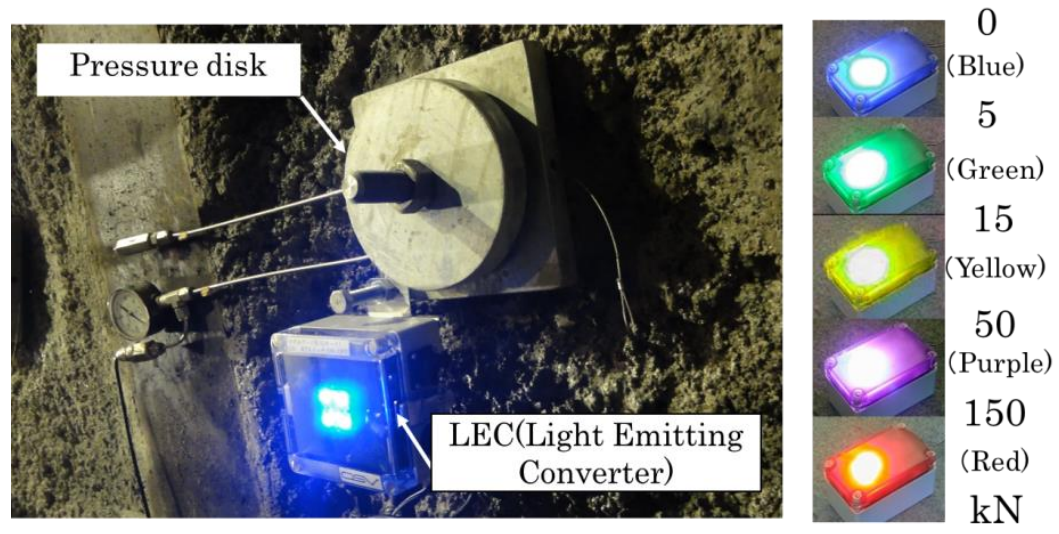

Figure 16 External appearance of the system

Table 3 Specifications of the pressure disk

\begin{tabular}{cc}
\hline External diameter $(\mathrm{mm})$ & 150 \\
Centre hole diameter $(\mathrm{mm})$ & 60 \\
Pressure receiving area $\left(\mathrm{cm}^{2}\right)$ & 95.2 \\
Maximum load $(\mathrm{kN})$ & 500 \\
\hline
\end{tabular}




\subsection{Laboratory performance confirmation tests}

First, laboratory tests were conducted in order to confirm that this system was operating properly under the load conditions assumed at the site. As a result, it was found that the load acting on the rockbolt plate and the coloured light emitted by the data converter were functioning correctly. The right side of Figure 16 shows the relation between the acting load and the emitted light colour that were set for the data converter in the laboratory tests.

\subsection{Results of onsite application}

Next, the results of the application to an actual tunnel site were examined. The geology of the tunnel where this system was applied consists of inconsistently softened, finely fractured mudstone. And the suitability of the support pattern was a concern. At this site, the conventional axial force measurements have been planned. Therefore, application tests were conducted at the same cross-section in order to verify the accuracy and suitability of this new system. Figure 17 shows rockbolt axial forces that were derived with a conventional method and values measured with the new system in the dotted frame. Figure 18 shows comparisons of temporal changes in axial force values between rockbolt values measured at a depth of one metre (conventional method) and measured with the new system. From these results, we can see that the axial force values derived from the two methods were in rough agreement, as were the periods of occurrence. Next, Figure 19 shows a comparison of the axial force values when the equipment was removed while there was a load. We can see that at depths between one and two metres, there was a slight decrease in axial force. However, a safety evaluation confirmed that there was no adverse effect. These results prove that there was no problem with the suitability and measuring accuracy of this system at an actual site.

Figure 20 shows conditions of installing this system on the left and right sides of a tunnel wall. We can see that the emitted light colour differed between left and right. In other words, in this particular tunnel zone, the tunnel was under a load that was being subjected to asymmetrical pressure. As a result, ways of effectively increasing support were considered.

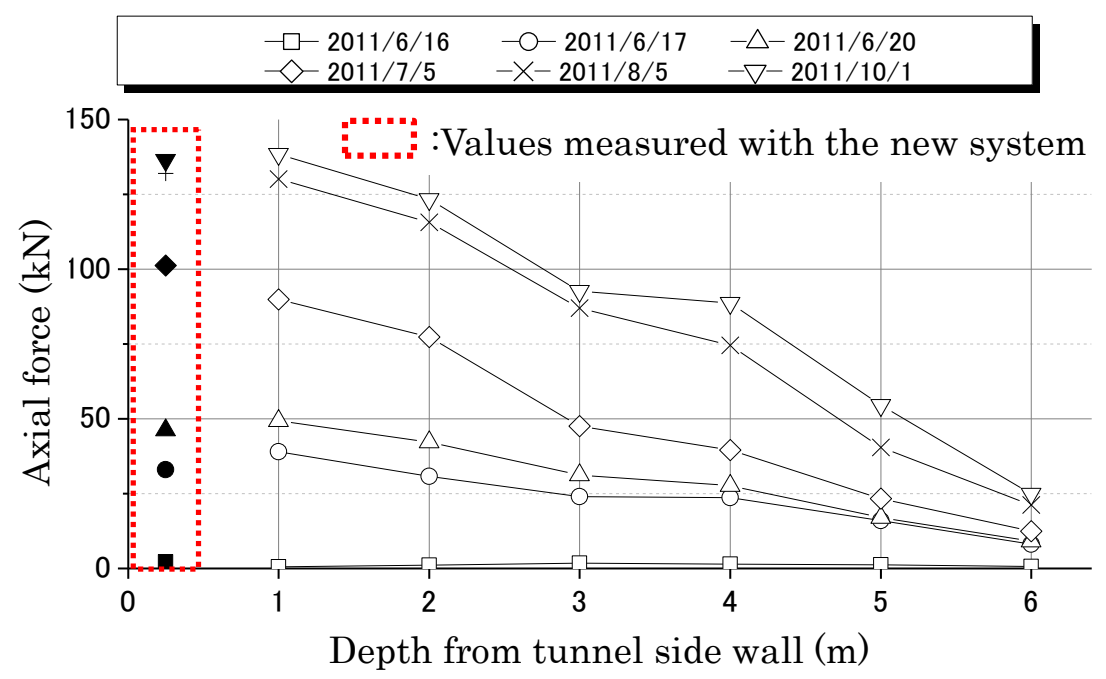

Figure 17 Comparisons of the rockbolt 


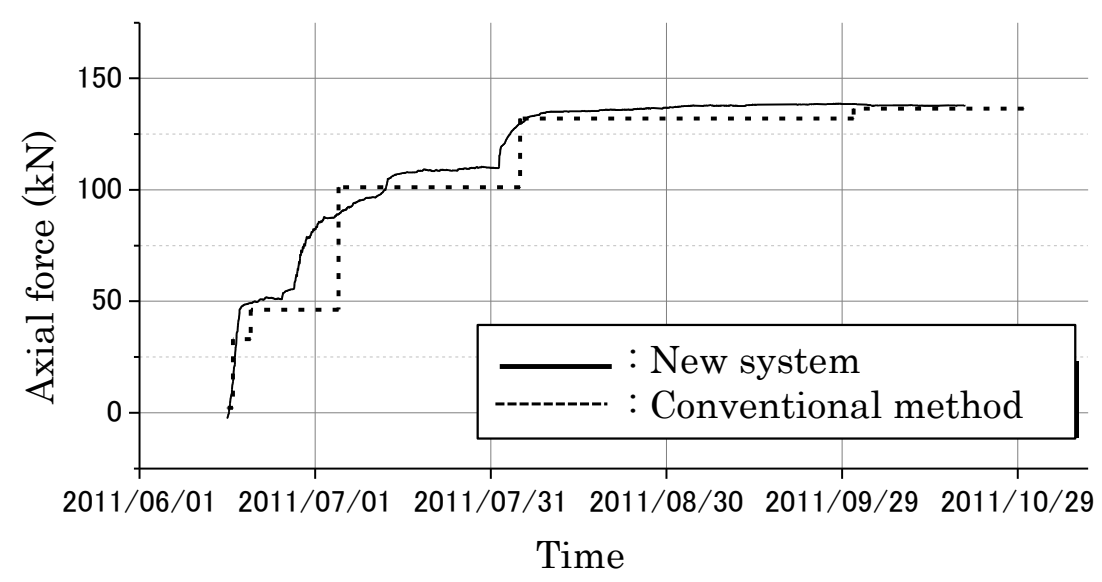

Figure 18 Comparisons of temporal changes axial force

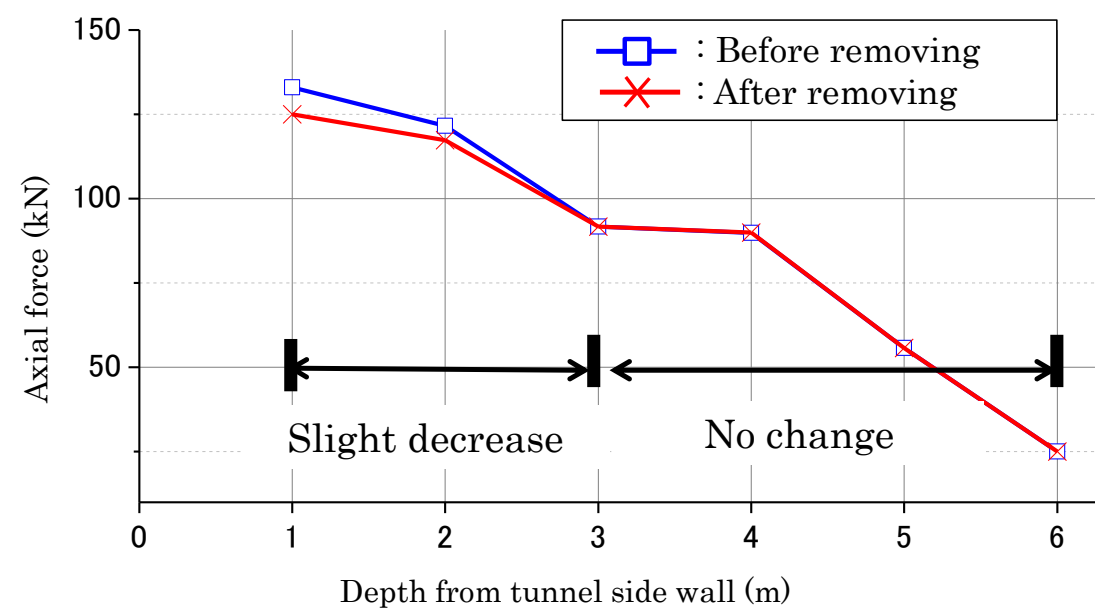

Figure 19 Comparisons of the axial force

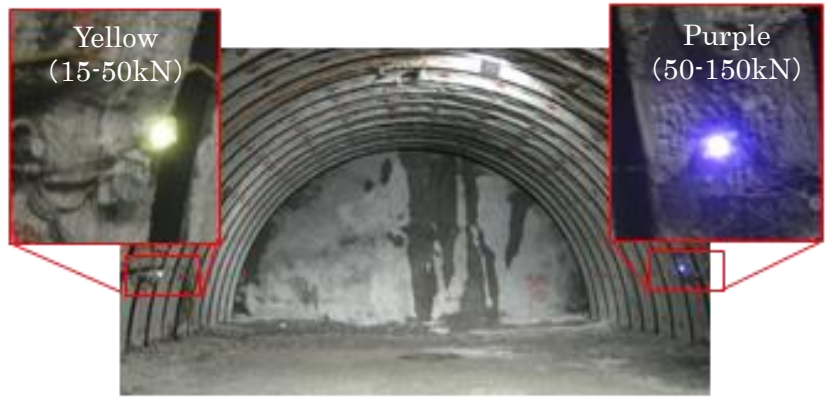

Figure 20 Conditions of installing values when the equipment was removed new system

\section{$4 \quad$ Summary}

The present study was conducted to improve the quality of rockbolting by developing 1) a technique using ultrasonic waves for evaluating the installation conditions of rockbolts anchored with mortar, 2) highfriction anchored rockbolts using checkered steel pipes to increase bonding strength, and 3) a method for measuring the axial force of rockbolts in real time at an actual work site. The following conclusions were made. 


\subsection{Technique using ultrasonic waves for evaluating the installation conditions of rockbolts anchored with mortar}

In the laboratory tests, the small reflective signals were remarkable when there was a decrease in filling ratio, and there was great variance in the wave patterns of each oscillating frequency used. When the head side of a rockbolt was unfilled, small reflective waves generated were large, even if only a small part was unfilled.

The field tests could estimate the filling conditions, even at an actual site.

It was possible to use this method to evaluate the soundness of rockbolts by estimating the filling ratio and areas that were unfilled.

\subsection{Development of high-friction anchored rockbolts using checkered steel pipes to increase bonding strength}

Pull-out tests were conducted both in the laboratory and in situ. The bonding strength that was obtained from the high-friction anchored rockbolts using checkered steel pipes was about twice as high as that provided by conventional normal friction anchored rockbolts. In addition, the pull-out load did not decrease after the initial pull-out strength peak was reached. Also the high friction anchored rockbolts using checkered steel pipes showed excellent properties, based on the load-displacement curve before the initial pull-out strength peak was reached.

Granular DEM analyses that were conducted to evaluate the reinforcement mechanism indicated that tensile and shear cracking occurred when there was pull-out from the vicinity of the protruding sections of the high-friction anchored rockbolts. By transferring the load to a wider area in the ground, this helped to better disperse the concentration of stress near the rockbolts compared with conventional methods. As a result, it was concluded that there was an improvement in the bonding strength of the new bolts.

Case studies of onsite applications showed no problems with water pressure decreasing as water was being injected. There were no problems with insertability, either.

\subsection{Development of a simplified axial force measurement device using an LEC}

Comparisons were conducted with conventional equipment for measuring the axial force of rockbolts at an actual site. As a result, the axial force values derived from the two methods were in rough agreement, as were the periods of occurrence.

In addition, the use of specially-developed nuts enabled the equipment to be taken out and moved to the next location, even under load conditions.

The use of the new measuring equipment can enable anyone to make real-time evaluations of the effects of rockbolts at work sites.

Mountain tunnelling methods are used in large section tunnels, difficult ground conditions such as squeezing ground, and even in urban areas where there is soft ground. The role of tunnel support materials such as rockbolts is increasing in importance. As a result, the authors have been working to research and develop methods for improving the quality of rockbolting. They would like to conduct further case studies of the application of their methods at actual sites and further improve the techniques and technologies in order to help make mountain tunnel work more effective and efficient.

\section{References}

Mori, T., Nakajima, M. and Tsutsui, T. (2007) Ultrasonic Technique for Rock Bolt and Rock Mass Bond Quality Control, in Proceedings International Conference on Ground anchorages and Anchored structures in service, November 2007, London, UK, ICE, London, pp. 231-237. 
Yokota, Y., Date, K. and Yamamoto, T. (2011) Verification of reinforcing effects of a tunnel face reinforcement method by centrifuge model tests and numerical analysis, in Proceedings 12th ISRM International Congress on Rock Mechanics, 18-21 October, Beijing, China, pp. 2,173-2,176. 
Instrumentation 